\title{
A jangada de pedra: uma mensagem político-ideológica
}

\author{
Maria do Carmo Pascoli \\ Universidade Federal da Bahia
}

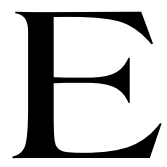

m Cerbère, região dos Pireneus Orientais, os cães não ladram. Descendem do cão de três cabeças, guardião da entrada do inferno, chamado Cérbero por seu tratador, o barqueiro Caronte. Em função dessa estranha linhagem, os cães se tornaram mudos e os habitantes dessa região acreditam, desde sempre, que se os cães puderem, algum dia, voltar a latir, este será o sinal de que o mundo estará prestes a acabar.

Essa lenda dá início ao romance $A$ jangada de pedra e a ela somamse outros cinco acontecimentos extraordinários que, juntos, indicam o início de uma transformação grandiosa na geografia do planeta terra: a Cadeia dos Pireneus se rompe e a Península Ibérica começa a movimentarse, deixando para trás o restante da Europa.

A narrativa segue vários caminhos, obedecendo a um tipo de construção, na qual inúmeros elementos, sejam do presente ou do passado, da vida real ou imaginária, convivem, vezes aproximados, outras lado a lado, seguindo um ritmo profuso, repleto de informações, de fatos e lembranças. Não encontramos os assuntos organizados linearmente, são múltiplos e simultâneos como os sons da ópera, de forma que a leitura de A jangada de pedra pede um "ouvido" atento, sintonizado com a diversidade de sentidos.

Os primeiros "acordes" são dados pela lenda e por fatos extraordinários: os cães anunciam o início das rachaduras, ocorridas nas montanhas rochosas, que parecem ter sido desencadeadas pelo gesto, aparentemente insignificante, de Joana Carda, realizado a muitos quilômetros da Cadeia dos Pireneus. A moça pegou ao acaso uma varinha, dessas comuns, que servem simplesmente para movimentar as mãos durante passeios ociosos, e fez um risco no chão. Neste mesmo instante, os cães mudos da pequena região de Cerbère, descendentes do famoso 
ancestral grego, começaram, repentinamente, a ladrar - anúncio de grande catástrofe, segundo os moradores da região.

O risco, aparentemente insignificante, que guardava o mistério de sempre se reconstituir depois de apagado, dá início a um estranho processo: fendas e mais fendas aparecem na Cadeia dos Pireneus e pouco a pouco, lentamente, a enorme massa de terra começa a se afastar da Europa. Se, a princípio, as rachaduras da cordilheira parecem ser um fato mágico e extraordinário, logo percebemos que não é somente esse o tom da narrativa, há um sentido mais amplo envolvendo o rompimento geográfico. A península, transformada em jangada, desliga-se do velho continente, como um barco aventureiro que abandona a calmaria do cais e parte em busca de novos horizontes.

A Europa e o mundo se dão conta de que os ibéricos, simplesmente, resolveram partir e que não há mais acordos a serem respeitados ou exigências possíveis diante de tal situação: uma península solta no mar, navegando sem leme ou destino certo. Desgarrados, se tornam autônomos e devem ser, por isso, auto-suficientes, sem dependências econômicas ou políticas e capazes de decidir seu próprio destino. A imensidão das águas oferece a possibilidade de mudança e a saciedade para a renovada busca do inquieto Portugal que, ao dizer não à Europa, busca, novamente, no caminho marítimo, a possibilidade de resolução de seus problemas.

A tentativa de compreender os motivos de tão drástica separação, nos leva aos principais acontecimentos políticos, ocorridos no século XX. Encontramos um Portugal em transe, vivendo dificuldades econômicas, como viveu em outros tempos, mas se a história se repete, haveremos de atentar às particularidades desse momento de desequilíbrio. O país enfrentou uma grave crise sócio-econômica decorrente do regime político ditadorial instituído por Salazar e continuado por Marcello Caetano, que assumiu a chefia do governo em 1968. A escolha do sucessor de Salazar passou pela avaliação das Forças Armadas, os ministros militares foram ouvidos e uma das disposições, que assegurava a continuidade do regime, era não aceitar qualquer afrouxamento na política de defesa e integridade do ultramar. A continuidade da guerra na África com o intuito de manter o poderio colonial era regra básica e um fator de coesão do poder instituído por Salazar; entretanto a guerra já durava treze anos e o déficit comercial agravava-se, na medida em que o Estado não conseguia arcar com as despesas, cada vez mais pesadas, que os conflitos em África infringiam, de forma que a manutenção dos territórios ultramarinos sob 
administração portuguesa tornava-se completamente inviável. Nas palavras do historiador José Mattoso:

...Lisboa estava prisioneira do que se passava em África. De facto, Lisboa, desde a década de 60, mais que a capital de um império colonial, estava subjugada por este, gastando na defesa diplomática e militar da manutenção da soberania política o melhor de seu tempo e energia. ${ }^{1}$

Verificamos que o processo de descolonização tornou-se imprescindível e só pôde ter efeito com a queda do regime político de Salazar. O movimento de 25 de abril de 1974 veio dar um fim à administração ditadorial e corporativista, que já durava meio século, e ao condicionalismo industrial que levou o país a uma crise insustentável. É importante lembrar que esse movimento, na prática, não correspondeu ao sonho português de uma revolução social que pudesse recuperar o atraso histórico da economia portuguesa, tendo como referencial, obviamente, o nível de vida europeu.

Ao traçarmos um paralelo entre os fatos do romance e os acontecimentos envolvendo a sociedade portuguesa do século XX, veremos que a ficção reescreve a história, não na ordem de ocorrência dos fatos, mas de acordo com o direcionamento que a criatividade do escritor estabelece. No romance, são as implicações sociais e econômicas causadas pelo desgarre da península, que causaram a crise do governo. A notícia de que a enorme jangada avançava em direção aos Açores, e que provavelmente haveria uma calamidade, se viesse realmente a se chocar, foi o motivo para o governo português se demitir:

...com fundamento na evidente gravidade da conjuntura e no perigo coletivo iminente, o que permite pensar que os governos só são capazes e eficazes nos momentos em que não haja razões fortes para exigir tudo de sua eficácia e capacidade. ${ }^{2}$

A avaliação do narrador reconhece a incapacidade dos governos de agirem adequadamente nos momentos de crise e perigo. Isto fica ainda mais claro, quando diz:

\footnotetext{
${ }^{1}$ MATTOSO, [s.d.], p. 95.

${ }^{2}$ SARAMAGO, [s.d.], p. 200.
} 
Os governos de Salvação Nacional são também muito bons, pode-se mesmo dizer que são os melhores que há, lástima é que as pátrias só de longe em longe precisam deles, por isso não temos habitualmente governos que nacionalmente saibam governar. ${ }^{3}$

Em A jangada de pedra, o governo de Salvação Nacional enfrenta o descrédito do narrador que avalia a possibilidade do tal governo ser bem sucedido na empreitada de "salvar" o povo, dizendo que não se podem evitar "certas manifestações de cepticismo congênito", já que todos conhecem o elenco ministerial. O narrador duvida da competência da equipe administrativa e, embora essa crítica se dê no plano da ficção, fica evidente que Saramago alude a importantes acontecimentos que fizeram parte da história portuguesa recente e consegue incorporá-los à narrativa, a partir da ótica irônica que lhe é característica.

O traço mais ostensivo das referências feitas pelo narrador à política e aos governantes portugueses é a ironia, termo que, em literatura, conforme concepção de Northrop Frye, ${ }^{4}$ indica uma técnica de rebaixamento, utilizada para, dizendo o mínimo, significar o máximo possível. Ainda de acordo com Frye, o olhar irônico volta-se para um horizonte limitado e denuncia suas falhas. No caso específico de Saramago, a afirmação irônica dá-se de forma indireta e não se explicita o julgamento moral. Frye define o "ironista exigente" como aquele que apenas afirma, deixando que o próprio leitor acrescente a condenação irônica. Este é o narrador de Saramago, embora seu discurso demonstre familiaridade com os fatos, posiciona-se como alguém que apenas reflete sobre determinadas situações, deixando para o olhar do leitor a identificação do ponto nevrálgico que a narrativa procurou sutilmente sugerir.

Em A jangada de pedra, subjacente à postura indiferente e descontraída do narrador irônico, encontramos interligadas história e ficção. Obviamente não se trata de uma resenha dos acontecimentos políticos, mas é possível reconhecer, no contexto da ficção, passagens do movimento revolucionário que derrubou a ditadura de Salazar. A demissão do governo português de $A$ jangada de pedra e a reflexão sobre a inoperância administrativa dos governantes, por exemplo, nos recorda

\footnotetext{
${ }^{3}$ SARAMAGO, [s.d.], p. 201.

${ }^{4}$ FREY, 1957, p. 47.
} 
que, durante o 25 de abril, o governo, então instituído em Portugal, diante da certeza de que haveria um golpe militar, postou-se como se não tivesse nenhum interesse em frear as movimentações revolucionárias. Pouca, ou nenhuma resistência foi oferecida às Forças Armadas que tomavam o país. A vitória foi alcançada pela aceitação pacífica dos que apoiavam o regime, tendo sido reconhecida a superioridade militar e política dos revolucionários. Conforme análise do historiador: "As resistências das forças fiéis ao governo são pouco mais que simbólicas e de certa maneira parecem contar com a generosidade antecipada dos vencedores."

Os ministros militares e o próprio Marcello Caetano entregaram, pacificamente, o poder ao General Spínola e aguardaram que uma escolta os fossem buscar para serem levados sob prisão ao Quartel de Engenharia I, onde Marcello Caetano declarou: "Se não fossem as circunstâncias em que isso se deu, a única sensação que teria era a de alívio, pois só estava a receber más notícias de todos os setores."

As "más notícias" decorriam das relações entre o Estado Novo conduzido por Marcello Caetano e um grupo de oficiais-generais, que pretendiam a redefinição dos objetivos nacionais quanto aos problemas de manutenção dos territórios ultramarinos, questão crucial na vida política portuguesa e que, como vimos, é quase obsessiva no imaginário português.

No texto de Saramago, após a demissão do governo, o primeiro ministro declarou ao país que, diante das dificuldades ocasionadas pelo desgarre da península, seria mais adequada a criação de um Governo de Salvação Nacional com participação de todas as forças políticas,

tendo em conta que sempre se encontraria um lugar de subsecretário adjunto de qualquer secretário adjunto de qualquer adjunto ministro para ser entregue à formações partidárias que, numa situação normal, não seriam chamados nem para abrir uma porta. ${ }^{7}$

Tanto na ficção quanto na história documentada, o governo português, diante de reais dificuldades, resolveu abster-se de qualquer ação política, deixando o problema para quem quisesse resolvê-lo, mesmo que isso significasse entregar a administração do país aos opositores políticos.

${ }^{5}$ MATTOSO, [s.d.], p. 28.

${ }^{6}$ MATTOSO, [s.d.], p. 30.

7 SARAMAGO, [s.d.], p. 200-201. 
A junta de salvação Nacional que, no romance, ganha uma nota irônica, foi constituída, após o fim do regime, no único órgão de soberania revolucionária e, embora tenha tornado visíveis as forças políticas e sociais que se opunham à ditadura, enfrentou intensa manifestação dos trabalhadores à procura de novas formas de organização sindical. Em decorrência, ocorreram inúmeras greves, que afetaram seriamente as indústrias. O país necessitava de medidas eficazes para a reorganização da economia e, entre as muitas tentativas administrativas ensaiadas nesse período conturbado, a adesão de Portugal à Comunidade Econômica Européia pareceu ser uma solução para todos os problemas. Significava a possibilidade de implantação de leis básicas que trariam benefícios à comunidade, por isso as políticas posteriores à revolução tiveram como prioridade a inserção do país no espaço das relações econômicas internacionais. A adesão de Portugal à Comunidade Econômica Européia possibilitaria, teoricamente, a participação do país nas relações internacionais e no grupo dos ricos da economia mundial.

A narrativa de $A$ jangada de pedra parece referir-se a essa questão, na passagem em que ocorre uma reunião da Comunidade Econômica Européia para discutir como ficariam os acordos econômicos tratados anteriormente; já que a Península Ibérica afastava-se fisicamente da Europa. O narrador observa que alguns países membros chegaram a manifestar um certo "desprendimento", durante o debate sobre a manutenção dos acordos em vigor e chegaram a insinuar que: "...se a Península Ibérica se queria ir embora, então que fosse, o erro foi tê-la deixado entrar." ${ }^{8}$

O autor continua mostrando que os comissários portugueses e espanhóis ficaram indignados com a postura indiferente dos países membros e, que cada qual, em sua língua, repetiram o conhecido ditado ibérico "Os amigos são para as ocasiões". "E óbvia a crítica de Saramago à crença disseminada em Portugal a respeito dos benefícios que iriam supostamente advir da "solidariedade atlantista". De fato, vemos que as negociações efetuadas por Portugal, para o estabelecimento do contrato de adesão à CEE, encontraram inúmeros obstáculos. À rapidez com que se decidiu pela adesão, seguiu-se a lentidão das negociações que se arrastaram por 8 anos, desde o pedido em 1977 até às conclusões em 1985. Saramago falou sobre o assunto:

\footnotetext{
${ }^{8}$ SARAMAGO, [s.d.], p. 42.

${ }^{9}$ SARAMAGO, [s.d.], p. 43.
} 
A idéia de uma Europa que nos iria levar no colo e que iria resolver todos os nossos problemas (...) conduziu-nos a quê? Conduziu-nos ao prolongamento da situação anterior, num quadro diferente. Por que antes era o jogo das potências no qual não tínhamos importância nenhuma; agora, é um suposto jogo de concerto e de acordo geral em que nós participamos, mas que também continuamos a não ter importância nenhuma. ${ }^{10}$

A visão do escritor corresponde à quebra das expectativas de que Portugal poderia ser aceito na CEE como membro participativo e operante, recebendo os mesmos benefícios que os componentes mais fortes e mais antigos. Uma série de entraves durante o processo de adesão e os acordos favorecendo sempre e muito mais as economias ricas mostraram que o tratado de adesão não se firmava em bases solidárias; as dificuldades "começaram a desenganar os que sonharam ir receber a Bruxelas uma pensão de tranqüila reforma por um império acabado e uma revolução desfeita." 11

Contrariando a ansiedade portuguesa, a CEE não teve pressa na condução do processo e não concedeu nenhum benefício a Portugal que pudesse prejudicar as negociações que travava em paralelo com a Espanha. Em março de 1984, o conselho de ministros da CEE declarou fechar as negociações com Portugal e Espanha até 30 de setembro, o que tornou claro que tratariam igualmente os países ibéricos, tanto que o tratado de adesão foi assinado por Portugal no dia 12 de junho de 1985 e, no mesmo dia à tarde, a Espanha entrou para a CEE. Além disso, as duas economias da península passaram a ter um quadro institucional que estimulou a sua integração, como por exemplo, a condição imposta a Portugal de não ter mais direitos aduaneiros em relação à Espanha.

Logo, é perfeitamente compreensível que os países ibéricos estejam juntos na jangada de Saramago e no adeus à Europa. Da mesma forma nos parece adequada a coloração pejorativa dada às relações internacionais, e também o tom constantemente irônico do narrador, que cresce, substancialmente, quando ele trata das negociações com os países europeus.

\footnotetext{
${ }^{10}$ REIS, 1998, p. 147.

${ }^{11}$ REIS, 1998, p. 166.
} 
No caso do encontro dos especialistas da França e Espanha, por ocasião do alargamento das fendas que deram início à ruptura das rochas, Saramago mostra maneiras de ser e reagir muito distintas, como que a identificar "quem é quem" nessa história. Os franceses são os "vizinhos astutos e cartesianos", capazes de nomear acertadamente as primeiras providências objetivas a serem tomadas para resolver o problema das rachaduras: "colmatar a brecha" - para o narrador: "nunca expressão alguma pode ser tão rigorosa, por isso francesa, chega-se a pensar que alguém a pensou, algum dia, ou inventou, para vir a ser usada com plena propriedade, quando a terra se rachasse."12 Os "vizinhos", além de astutos, são insolentes - o jornalista, "Michel e cínico", disse a seu colega espanhol, "sério e Miguel", que ficassem com a fenda já que estavam tão precisados. Eles, os franceses, não necessitavam de "furos artesianos virados ao contrário", ${ }^{13}$ só no Cirque de Gavarnie tinham uma cascata de 400 metros de altura.

O narrador torna-se ainda mais agudo ao relatar as negociações entre Portugal, Espanha e os países da OTAN, a propósito do pedido feito pelos países peninsulares de uma declaração de solidariedade atlantista, quando a situação dos dois países parecia desesperadora. O narrador, ironicamente, diz que a resposta foi apenas uma frase impublicável: "Wait and see". ${ }^{14}$ Esse "espere e veja" nos remete novamente às negociações de adesão à CEE, na medida em que os trâmites do processo, que resultaram nas resoluções finais do Conselho Europeu, se deram de forma exasperadamente lenta. Somente um ano e meio depois do pedido de adesão, ocorreu a primeira reunião de embaixadores em Bruxelas e depois de quinze reuniões, as negociações ainda revelavam-se difíceis. Quatro anos depois de aberto o processo, a CEE "imersa na tentativa de alterar sua política para a agricultura mediterrânica entra em retiro espiritual." ${ }^{15}$

Finalmente, depois de inúmeras propostas e acordos, o tratado foi assinado e Portugal teve que aceitar condições que eram mais favoráveis às economias ricas. Foram feitas "cedências a mais que requerem compensações", ${ }^{16}$ afirmou a Confederação Industrial Portuguesa. Esta

\footnotetext{
${ }^{12}$ SARAMAGO, [s.d.], p. 26.

13 SARAMAGO, [s.d.], p. 22.

${ }^{14}$ SARAMAGO, [s.d.], p. 14.

${ }^{15}$ MATTOSO, [s.d.], p. 152.

${ }^{16}$ MATTOSO, [s.d.], p. 152.
} 
situação pode ser reconhecida no romance, quando Saramago relata o apelo feito por Portugal aos países "irmãos", que acolheram "com simpatia" o pedido e quiseram saber que tipo de auxílio os portugueses precisavam, ainda que a ajuda européia dependesse das suas "disponibilidades excedentárias". ${ }^{17}$

Vemos que a ironia perpassa cada frase, desnudando a hipócrita postura dos países europeus, verdadeiramente indiferentes a qualquer tipo de relacionamento amigo que não lhes traga benefícios. O narrador diz inclusive que graças a esse tipo de solidariedade internacional se evitou a fome em África - mentirosa, a afirmativa enfatiza a denúncia à insensibilidade dos países ricos diante da situação miserável dos povos de economia deficitária, especialmente os povos africanos.

Quando entrevistado por Carlos Reis, a propósito da relação PortugalEuropa, Saramago toca num ponto que julgamos essencial para a compreensão do tratamento que o narrador dá ao relato das "negociações" internacionais, em A jangada de pedra. Ele diz: "No que se refere à Europa, continuo a acreditar que ela é um grande engano, que é qualquer coisa que nos vai custar muito caro e que não posso aceitar". Mas ao mesmo tempo questiona:

Queria eu que se prolongasse e se mantivesse a situação anterior? Não, não desejaria que se mantivesse a nossa dependência estrutural, sendo Portugal um país débil, com uma economia débil, pouco importante ou nada importante no concerto geral das nações: esse foi sempre, a partir do século XVII ou XVIII, o nosso lugar e iria continuar assim. ${ }^{18}$

Tampouco lhe parece lucrativa a entrada de Portugal na CEE. Pergunta-se a quem serve a Europa e diz que não serve ao emprego, "porque já leva quase vinte milhões de desempregados" e que todos, na realidade, direta ou indiretamente, servem a uma macroeconomia das grandes empresas e multinacionais.

Para ele, esse é um jogo entre potências, sub-potências e meros satélites, como é o caso de Portugal e que, na verdade, se por um lado o conceito de cidadania se amplia com a participação do país na economia européia, por outro é ínfima a participação dos "novos cidadãos europeus",

\footnotetext{
${ }^{17}$ SARAMAGO, [s.d.], p. 202.

${ }^{18}$ REIS, 1998, p. 147.
} 
já que, na prática, Portugal está à margem da grande engrenagem. Ou seja, trata-se de uma ilusão de cidadania. Saramago relembra a esse respeito, um discurso do presidente Mário Soares, no qual ele se refere aos europeus como os duzentos ou quatrocentos (o escritor não está bem certo) milhões de "consumidores". Percebemos que para o escritor é muito difícil constatar que o discurso do dirigente político elege novos termos, como se no mundo globalizado, a palavra "cidadão" não fosse mais apropriada e tivesse que dar lugar a substituta "consumidor", mais condizente com o tipo de economia que se instaura.

\section{"O porto sempre por achar"19}

Em A jangada de pedra, a viagem da nação obedece a uma lógica baseada no poder e liberdade de escolha do povo português. O sentido para esse deslocamento da península tem como cláusula de sua existência o posicionamento do autor José Saramago diante da pseudo união européia; logo, dar as costas à Europa e seguir em direção à África e América do Sul pode ser muito significativo, considerando que Portugal volta-se para um espaço a que está ligado por laços históricos, culturais e lingüísticos.

A escolha de Portugal delineia-se e configura-se, se considerarmos os laços formados no passado distante, quando o mar era "desconhecido", anterior à configuração atual do mundo cujas regras estão subordinadas, não a uma nação, mas ao capital sem pátria. As regras de comportamento, de relações sociais, de gosto são construídas pelo domínio econômico, que vêm, pouco a pouco, se impondo absoluto. A "península" não deveria compactuar com esta forma de imperialismo.

Na visão do autor, a consciência cultural européia não é elo de união; fragilizada, parece perder terreno para a hegemonização cultural do planeta, instaurada pelo poder econômico, condicionador absoluto de uma nova ordem para a existência social e simbólica dos homens.

De acordo com Eduardo Lourenço, em O Esplendor do $\operatorname{Caos},{ }^{20} \mathrm{a}$ cultura ocupou, nos últimos dois séculos, o lugar da transcendência religiosa, tornando-se, por isso mesmo, expressão sacralizante da existência

\footnotetext{
${ }^{19}$ PESSOA, 1995, p. 27.

${ }^{20}$ LOURENÇO, 1999, p. 13-51.
} 
humana. De forma que, idealmente, a cultura não participava do processo econômico, isto é, cultura não era trabalho, mas atividade cujo valor não se estabelecia da mesma forma com que se determina o valor dos produtos de consumo em geral; porém a era da mundialização impôs ícones culturais determinados pelo domínio econômico, de forma que o sujeito encontra seu código cultural na imagem veiculada pelo poder financeiro. O signo cultural não se sustenta em nenhuma ideologia, senão a que rege as leis do mercado. Convertida em subproduto de processos rentáveis, as expressões da inteligência e espiritualidade humanas podem ser vistas como produtos de consumo, tendo como os demais, vida efêmera. Este esfacelamento cultural desintegra o que poderia ser considerado "bem" comum a todos os europeus e elo de união dos povos. Disse Saramago: "De tanto se dizer que tudo é cultura, quase acabou por se perder, na comunicação e na prática, o sentido da relatividade de valores dos diferentes actos e produtos culturais". ${ }^{21}$

Como definir, em meio a essa pulverização cultural, o que é europeu? O conceito, segundo Saramago, importaria, teria algum significado, se as bases de sustentação de uma Europa unida fossem igualdade de direitos e deveres de seus cidadãos. ${ }^{22}$ Portanto, o fato de Saramago romper com a Europa, em sua ficção, dando oportunidade aos ibéricos de escolher suas parcerias ou "vizinhos", de certa forma resgata um sentido de humanidade, perdido em meio às inúmeras etapas do desenvolvimento das atuais economias e reconstitui valores de união dos indivíduos, já que, necessariamente, os ibéricos estarão juntos na Jangada de Pedra O processo de crescimento social da macro-economia, que se alimenta da ausência de vontade e consciência crítica do ser humano, engendra o homem destituído de competência para avaliar seu papel e lugar no mundo.

Ilhar, de certa forma, as pessoas num lugar seguro, posto que conhecido e familiar, favorece as relações autenticamente humanas. A função positiva, sem dúvida, está em se criar uma resistência à universalização definida pelo jogo econômico indiferente a qualquer relação afetiva e desinteressada entre os sujeitos de uma sociedade. Parte dos milhões de excluídos das vantagens do triunfo econômico estão em A jangada de pedra de Saramago, por isso liberdade de escolha é o tom

${ }^{21}$ BERRINE, 1998, p. 236.

${ }^{22}$ BERRINE, 1998, p. 234-235. 
maior do romance, é o que torna possível o reencontro do homem com seu semelhante, dando-lhe a possibilidade do reconhecimento da sua própria natureza. E mais, é o que dá sentido à ruptura, à volta ao mar e à viagem que transforma situações e indivíduos.

O autor-cidadão português resolveu começar de "raiz" e de "berço". Deu à nova Península Ibérica poder de decisão, autonomia e um ideal para o futuro, que se pretende livre do absolutismo arbitrário, do convencionalismo e da anarquia de interesses alienados e egoístas. As pessoas nascem todos os dias, só delas é que depende continuarem a viver o dia de ontem ou começarem de raiz e de berço o dia novo, hoje. ${ }^{23}$

\section{Referências Bibliográficas}

BERRINI, Beatriz, Ler Saramago - O Romance. 2. ed. Lisboa: Caminho, 1998. FRYE, Northrop. Anatomia da Crítica. Trad. Péricles Eugênio da Silva Ramos. São Paulo: Cultrix, 1957.

LOURENÇO, Eduardo. O esplendor do caos. Lisboa: Gradiva, 1999.

MATTOSO, José. História de Portugal-Portugal em Transe. Coord. José Medeiros Ferreira. Lisboa: Editorial Caminho, [s.d.]. v. 8.

PESSOA, Fernando. Obra poética. Org. Maria Gallhoz. Rio de Janeiro: Nova Aguilar, 1997.

REIS, Carlos. Diálogos com José Saramago. Lisboa: Editorial Caminho, 1998.

SARAMAGO, José. A jangada de pedra. Rio de Janeiro: Record, [s.d.]. (Mestres da Literatura Brasileira e Portuguesa)

${ }^{23}$ SARAMAGO, [s.d.], p. 248. 


\section{Resumo}

Este estudo do romance A jangada de pedra de José Saramago parte do motivo da viagem como movimento transformador das situações e dos indivíduos. A interpretação da viagem empreendida pela península Ibérica, transformada em jangada na ficção de Saramago, privilegia a busca de um sentido pela escolha do caminho marítimo e o questionamento quanto aos motivos que teriam levado a península a romper os laços geográficos com a Europa. O trajeto pelo oceano simboliza a viagem existencial dos indivíduos e da nação portuguesa que procura firmar-se, em uma parte do planeta, no qual, possa determinar as próprias diretrizes, independente do jugo econômico imposto pelas macro-potências. A jangada de pedra, imaginada por Saramago, transporta os portugueses, que partem em busca de autonomia política, econômica e social, através do mar "novamente desconhecido".

\section{Abstract}

This study has of the José de Saramago's book The Stone Raft (A jangada de pedra) begins by exploring the reason of the trip as a transforming movement of the situations and the individuals. The interpretation of the trip as the Iberian peninsula, transformed into a raft in the Saramago fiction, privileges the search for sense in the choice of the maritime way and it questions the reasons which would have led the peninsula to break the geographic ties with Europe. Its way through the sea symbolises the existential trip of the individuals and of the Portuguese nation which is trying to become significant somewhere within the planet, where it may determine its own laws, independent from economical demands from the great nations. The stone raft that was imagined by Saramago, transports the Portuguese that leave their nation in search for political, economical and social autonomy, throughout the sea that is "once again unknown". 